\title{
Anti-Hu antibody titre and brain metastases before and after treatment for small cell lung
} cancer

Jan J Verschuuren, Mark Perquin, Guul ten Velde, Marc De Baets, Peter van Breda Vriesman, Albert Twijnstra

\begin{abstract}
Objectives-To follow up the level of anti-Hu antibody titres during chemotherapy and to compare the pattern of metastases and other neurological complications before and after chemotherapy in patients with small cell lung cancer (SCLC) with and without low titre anti-Hu antibodies. Seventeen per cent of patients with SCLC without paraneoplastic syndromes have a low titre of anti-Hu antibodies in their serum. Previous studies suggested that these antibodies correlate with a more indolent tumour growth. Methods-The serum of 52 consecutive patients with SCLC were studied before and during chemotherapy, and the correlation with stage of disease and pattern of metastases was examined. All serum samples were investigated using western blot and enzyme linked immunosorbent assay (ELISA) with HuD recombinant protein. All patients with SCLC were investigated using MRI of the brain, CSF, bone marrow aspiration, ultrasound of the abdomen, and radionuclide bone scan.

Results-Nine (17\%) of 52 SCLC serum samples were positive by western blot. At the time of diagnosis none of the anti-Hu positive patients had either CNS (brain or leptomeningeal), epidural, adrenal, or bone marrow metastases and $56 \%$ had limited disease. In eight of 43 anti-Hu negative patients CNS metastases were found at the time of diagnosis, and only $30 \%$ had limited disease. The prevalence of bone and liver metastases was similar in both groups. Survival was 11 (SD) months for the 43 anti-Hu negative and 10 (SD 6) months for the nine anti-Hu positive patients. Male:female ratio in the anti-Hu negative group was $4.4: 1$, and in the anti-Hu positive group $2: 1$.
\end{abstract}

Conclusions-No anti-Hu antibody positive serum, as tested by western blot, became negative during chemotherapy. Anti-Hu positive and anti-Hu negative patients had similar survival, but anti-Hu positive patients tended to be women, had limited disease at the time of tumour diagnosis, and initially metastases seemed to spare the nervous system.

(F Neurol Neurosurg Psychiatry 1999;67:353-357)

Keywords: small cell lung cancer; anti-Hu antibody; metastases
The presence of a high titre of anti-Hu antibodies in the serum of a patient with a sensory neuronopathy or a limbic encephalitis strongly suggests that the patient has a paraneoplastic complication of an underlying small cell lung cancer (SCLC). ${ }^{1}$ A study in 71 patients with these paraneoplastic syndromes showed that $69 \%$ of the patients had a tumour too small and localised to be responsible for the patient's death, suggesting that the cancer is more indolent than in patients who do not have a paraneoplastic syndrome. ${ }^{1}$ The anti-Hu immune response, of which anti-Hu serum antibodies are a specific marker, seems to protect against death by the tumour. However, the devastating nature of the paraneoplastic syndrome gives these patients with high titres of anti-Hu antibodies a median survival similar to that of patients who have SCLC without the paraneoplastic syndrome. ${ }^{1}$

Recently, it was found that about $16 \%-17 \%$ of patients with SCLC without paraneoplastic syndromes, have a low titre of anti-Hu antibodies. ${ }^{2-4}$ This shows that also patients with SCLC without clinically manifest neurological paraneoplastic syndromes can develop an anti-Hu immune response. The survival of these patients will not be influenced by the presence of severe neurological disorders. Thus, if indeed the anti-Hu immune response helps in controlling the growth of the tumour, it can be expected that this group of patients with a low titre of anti-Hu antibody has a more indolent tumour growth. This was recently confirmed in a large prospective study of patients with SCLC. ${ }^{4}$

To determine the prevalence of anti-Hu antibodies, the titre during chemotherapy, and the relation with stage of disease and metastases, we studied 52 consecutive patients with SCLC .

Material and methods

PATIENTS AND SERUM SAMPLES

From December 1990 to January 199552 patients with newly diagnosed SCLC whose serum could be obtained at the time of diagnosis were included in the study.

Initial staging of these patients by a pulmonologist was based on physical examination, routine blood and chemistry profile, chest radiography, CT of the chest, ultrasound of the abdomen, radionuclide bone scan, fiberoptic bronchoscopy, and bone marrow aspirate and biopsy.

Limited disease was defined as tumour confined to one hemithorax, including the 


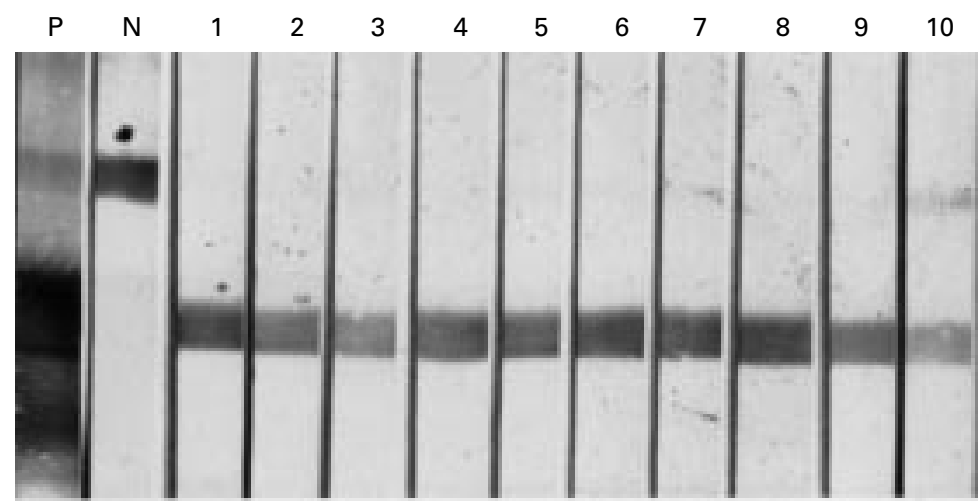

Figure 1 Results of western blot using purified HuD1 protein. From left to right the lanes show high titre anti-Hu serum as positive control serum $(P)$, normal human serum as negative control $(N)$. Lanes marked 1-10 show consecutive serum samples from patient 6 , obtained on 22 fanuary (1), 28 fanuary (2), 11 February (3), 22 February (4), 22 March (5), 24 April (6), 22 May (7),28 August (8), 3 December (9), and 19 December (10).

mediastinum, the ipsilateral or contralateral scalene, and supraclavicular lymph nodes. Patients with pleural effusion were categorised as limited disease. In extensive disease tumour was found beyond these sites.

Patients were seen by a neurologist at the time of diagnosis and at three monthly intervals (biannually after 1 year). A pretreatment MRI of the brain was performed. Other neurological consultations or diagnostic tests took place as required.

From each patient with SCLC a serum sample, obtained before chemotherapy, was tested by western blot for the presence of anti-Hu antibodies. Serum samples from anti-Hu antibody positive patients, obtained during and after chemotherapy were tested by western blot and enzyme linked immunopsorbent assay (ELISA) for the presence of anti-Hu antibodies.

\section{WESTERN BLOT}

Western blots using purified $\mathrm{HuD}$ fusion protein were performed as described previously. $^{2}$

Serum was tested at a dilution of 1:1000. After overnight incubation the strips were incubated with goat antihuman IgG at 1:2000 and

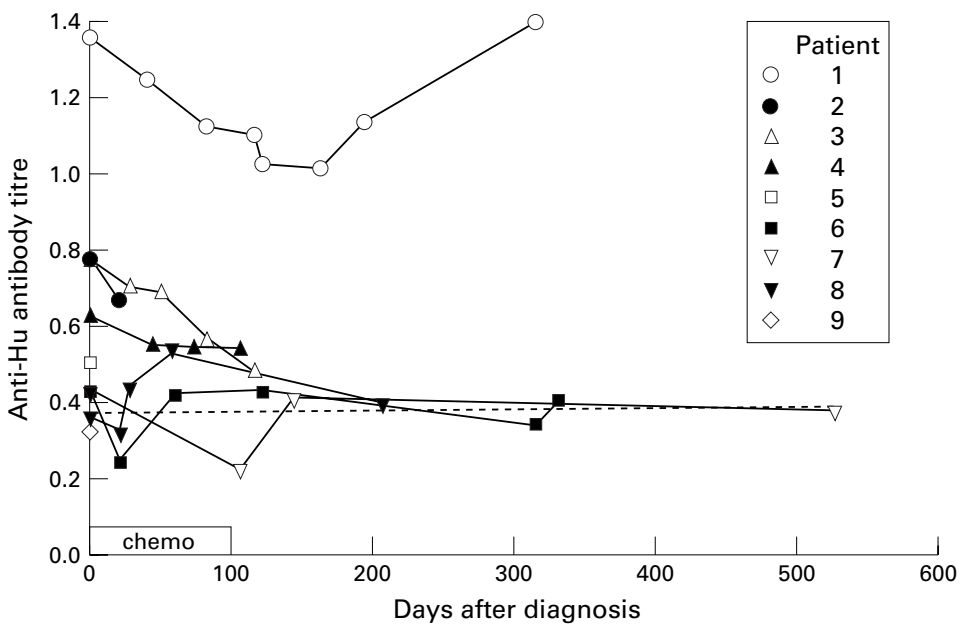

Figure 2 Anti-Hu antibody titres determined by ELISA using purified HuD1 protein and serum at 1/500 dilution. Results are shown for the nine serum samples which were found positive by western blot with $\mathrm{HuD} 1$ protein. The dotted line represents the mean of normal control serum plus 2 SD. The $x$ axis shows the days after tumour diagnosis, and the $y$ axis shows the mean of the $O D 450 \mathrm{~nm}$ absorption values. with avidin labelled with horse radish peroxidase. Control serum included one paraneoplastic patient with high titre of anti-Hu antibodies, five patients with systemic lupus erythematosus, and nine normal subjects. Reactivity was scored blindly by three investigators as mild(+), moderate $(++)$, or intense $(+++)$.

ELISA

The ELISA was performed as described previously, with some modifications. ${ }^{4}$ Polyvinyl 96 well microtitre plates (ICN) were coated with $50 \mu \mathrm{l}$ purified recombinant $\mathrm{HuD}$ at a concentration of $10 \mu \mathrm{g} / \mathrm{ml}$ for 1 hour at $37^{\circ} \mathrm{C}$. After washing with wash buffer (phosphate buffered saline (PBS) containing $0.5 \%$ Tween-20 (Sigma) and $0.1 \%$ bovine serum albumin (BSA) (Sigma), plates were incubated with 200 $\mu 1$ PBS with $0.1 \%$ Tween-20 and $1 \%$ BSA for 1 hour at room temperature (RT) on a shaker. Next $50 \mu \mathrm{l}$ of serum diluted in incubation buffer (PBS with $1 \%$ Tween-20 and $1 \%$ BSA) was incubated for 1 hour at RT on a shaker. Wells were washed eight times with wash buffer, and incubated with $50 \mu \mathrm{l} 1 / 8000$ dilution $(1 \mathrm{mg} / \mathrm{ml})$ of goat antihuman $\mathrm{IgG}$ coupled to horse radish peroxidase (Kirkegaard and Perry Laboratories Inc) for 1 hour at RT on a shaker. After washing again with wash buffer, the colorimetric reaction was developed by adding $100 \mu$ tetramethylbenzidine solution (Sigma). After 5 minutes the reaction was stopped by adding $100 \mu \mathrm{l} 1 \mathrm{M}$ phosphoric acid. Absorbance values were read at an optical density of $450 \mathrm{~nm}\left(\mathrm{OD}_{450}\right)$ using a Twin ELISA reader (Titertek). All ELISA studies were performed in duplicate, and the results expressed as the mean of two optical density (OD) ${ }_{450}$ absorption values. Each serum sample was tested at serial dilutions of $1 / 500,1 / 2000$, and $1 / 8000$. A dilution of $1 / 500$ appeared in the linear part of the absorption curve for all tested serum samples. A serum sample was considered positive if the $\mathrm{OD}_{450}$ absorption value was higher than 378 (mean of the normal human serum increased by $2 \mathrm{SD}$ ).

\section{STATISTICS}

Odds ratios were calculated according to Rothman and Greenland. ${ }^{5}$

\section{Results}

ANTI-HU ANTIBODY TITRES DURING AND AFTER CHEMOTHERAPY

Nine $(17 \%)$ serum samples from 52 consecutive patients with SCLC were found to be anti-Hu antibody positive in a western blot using purified $\mathrm{HuD}$ protein. One serum sample was scored as +++ (patient 1 ), two as ++ (patients 3 and 7 ); the other six were scored as + . From each of these nine patients one to nine serum samples, collected during or after chemotherapy, were tested. If a pretreatment serum was found to be positive, all the other serum samples from the same patient were also positive in the western blot. The western blot seemed more sensitive in detecting positive serum samples, which can be illustrated by the comparison of the western blot (fig 1) and ELISA (fig 2) of patient 6 . 
Table 1 Patient characteristics

\begin{tabular}{lll}
\hline & Anti-Hu negative & Anti-Hu positive \\
\hline Number of patients & 43 & 9 \\
Sex & 35 men, 8 women & 6 men, 3 women \\
Age of diagnosis (y) & $63(8.4)^{\star}$ & $59(8)^{\star}$ \\
Duration of disease (months) & $10(7)^{\star}$ & $10(6)^{\star}$ \\
Cause of death & $11 / 33$ neurological & $2 / 8$ neurological \\
Limited/extensive disease & $13 / 30$ (limited $30 \%)$ & $5 / 4$ (limited $56 \%)$ \\
Chemotherapy & $41 / 43 \dagger$ & $9 / 9$ \\
Response: & $13 / 41$ & $5 / 9$ \\
$\quad$ Complete remission & $20 / 41$ & $0 / 9$ \\
$\quad$ Partial remission & $1 / 41$ & $1 / 9$ \\
$\quad$ Stable disease & $9 / 41$ & $3 / 9$ \\
$\quad$ Progressive disease & $13 / 43$ & $7 / 9$ \\
Radiotherapy on primary tumour & &
\end{tabular}

${ }^{\star}$ Mean (SD).

†Two patients (77 years, 0.8 months survival and 54 years, 1.2 months survival) did not have chemotherapy.

Table 2 Neurological complications

\begin{tabular}{lll}
\hline & Anti-Hu negative & Anti-Hu positive \\
\hline Number of patients & 43 & 9 \\
Metastases at initial screening: & $8 / 43(19 \%)$ & $0 / 8^{\star}$ \\
$\quad$ Brain & $1 / 43(2 \%)$ & $0 / 8^{\star}$ \\
Epidural & $0 / 43$ & $0 / 8^{\star}$ \\
Leptomeningal & $2 / 43(5 \%)$ & $0 / 9$ \\
Adrenal & $6 / 43(14 \%)$ & $0 / 9$ \\
Bone marrow & $18 / 43(42 \%)$ & $5 / 9(56 \%)$ \\
Bone & $10 / 43(23 \%)$ & $3 / 9(33 \%)$ \\
Liver & $6 / 43(14 \%)$ & $1 / 9(11 \%)$ \\
Other & $30 / 43(70 \%)$ & $5 / 9(56 \%)$ \\
Any metastasis & $18 / 43(42 \%)$ & $5 / 9(56 \%)$ \\
Metastases at follow up & $2 / 43(5 \%)$ & $0 / 9$ \\
Brain metastases & $3 / 43(7 \%)$ & $1 / 9(11 \%)$ \\
Leptomeningal metastases & &
\end{tabular}

For patient 6 every second available serum was tested (22 January, 11 February, 22 March, 22 May, 3 December, and 19 December). For comparison see fig 1, respectively lanes $1,3,5,7,9$, and 10 .

An ELISA was used for a semiquantitive analysis of the antibody titres (fig 2). The pretreatment serum sample from two of these nine patients (patients 8 and 9) was positive in the western blot, but negative in the ELISA. Follow up serum of one of them became anti-Hu antibody positive in ELISA (patient $8)$. The serum with the highest anti-Hu antibody titre showed a decrease in titre (fig 2). After chemotherapy the anti-Hu antibody titres in patient 1 increased again.
NEUROLOGICAL COMPLICATIONS

The patient characteristics, pattern of metastasis, and reaction to chemotherapy are summarised in tables 1 and 2. The anti-Hu antibody positive group of patients contained relatively more women. At the time of diagnosis this group had more patients with limited disease $(56 \%)$ than the anti-Hu antibody negative group (28\%). None of the anti-Hu positive patients had either brain, epidural, leptomeningal, adrenal, or bone marow metastases at the time of diagnosis, whereas bone and liver metastases were similar in anti-Hu positive and negative patients. Overall, $56 \%$ of anti-Hu positive patients had metastases at the moment of diagnosis, whereas these were detected in $70 \%$ of anti-Hu negative patients. In addition, five of nine $(56 \%)$ patients showed a complete remission on chemotherapy, compared with only $13 / 41(30 \%)$ of anti-Hu negative patients. During follow up the initial difference in pattern of metastases disappeared, and finally the survival was similar in both groups.

The tumour of the patient with the highest anti-Hu antibody titre $\left(\mathrm{OD}_{450} 1367\right)$ was classified as having extensive disease at the time of diagnosis, and he had no paraneoplastic disease, but he survived for 17 months. He had a polyneuropathy, which developed after start of the chemotherapy. He died because of complications related to tumour growth.

To compare our data with other studies of patients with SCLC and low titres of serum anti-Hu antibodies, the results of three other studies describing these patients were compared and pooled (table 3 ). Together with our study, these reports describe a total of 376 patients.

More female patients were anti-Hu antibody positive $(33 \%$ v $23 \%$, odds ratio 2.0 (95\% confidence interval (95\% CI) 0.7-5.7)). Because of the low number of women in the study of Graus et al, the odds ratios was also calculated by excluding this study, which further increased the ratio to 2.4 (95\% CI $0.8-6.8$ ). Limited disease at the time of diagnosis was more frequent in the anti-Hu positive group $(68 \%$ v $37 \%$, odds ratio 3.0 (95\% CI 1.4-6.8)). Only one previous paper reported that no brain metastases were found at the time of diagnosis. $^{2}$

Table 3 Low titre anti-Hu antibodies in patients with SCLC without paraneoplastic disease

\begin{tabular}{|c|c|c|c|c|c|c|c|c|c|}
\hline & \multirow[b]{2}{*}{$n$} & \multirow{2}{*}{$\begin{array}{l}\text { Anti-Hu } \\
\text { antibody positive }\end{array}$} & \multicolumn{2}{|c|}{ Female sex } & \multicolumn{2}{|c|}{ Limited disease } & \multicolumn{2}{|c|}{$\begin{array}{l}\text { Initial CNS } \\
\text { metastases }\end{array}$} & \multirow[b]{2}{*}{ Reference } \\
\hline & & & $H u(+)$ & $H u(-)$ & $H u(+)$ & $H u(-)$ & $H u(+)$ & $H u(-)$ & \\
\hline Dalmau et $a l^{2}$ & 44 & $7(16 \%)$ & $\begin{array}{l}5 / 7 \\
71 \%\end{array}$ & $\begin{array}{l}16 / 37 \\
43 \%\end{array}$ & $\begin{array}{l}7 / 7 \\
100 \%\end{array}$ & $\begin{array}{l}0 / 37 \\
0 \%\end{array}$ & $\begin{array}{l}0 / 7 \\
0 \%\end{array}$ & $\begin{array}{l}10 / 37 \\
27 \%\end{array}$ & Dalmau et al \\
\hline Mason $e t a l^{3}$ & 110 & $19(17 \%)$ & $\begin{array}{l}11 / 17^{\star} \\
65 \%\end{array}$ & $\begin{array}{l}39 / 85^{\star} \\
46 \%\end{array}$ & $\begin{array}{l}14 / 19 \\
74 \%\end{array}$ & $\begin{array}{l}48 / 91 \\
53 \%\end{array}$ & NA & NAt & Mason $e t a l^{3}$ \\
\hline Graus et $a l^{4}$ & 170 & $27(16 \%)$ & $\begin{array}{l}1 / 27 \\
4 \%\end{array}$ & $\begin{array}{l}8 / 143 \\
6 \%\end{array}$ & $\begin{array}{l}16 / 27 \\
59 \%\end{array}$ & $\begin{array}{l}54 / 143 \\
39 \%\end{array}$ & NA & NA & Graus et $a l^{4}$ \\
\hline This study & 52 & $9(17 \%)$ & $\begin{array}{l}3 / 9 \\
33 \%\end{array}$ & $\begin{array}{l}8 / 43 \\
19 \%\end{array}$ & $\begin{array}{l}5 / 9 \\
56 \%\end{array}$ & $\begin{array}{l}13 / 43 \\
30 \%\end{array}$ & $\begin{array}{l}0 / 8 \\
0 \%\end{array}$ & $\begin{array}{l}9 / 43 \\
21 \%\end{array}$ & \\
\hline All studies & 376 & $62(16 \%)$ & $\begin{array}{l}20 / 60 \\
33 \%\end{array}$ & $\begin{array}{l}71 / 308 \\
23 \%\end{array}$ & $\begin{array}{l}42 / 62 \\
68 \%\end{array}$ & $\begin{array}{l}115 / 314 \\
37 \%\end{array}$ & $\begin{array}{l}0 / 15 \\
0 \%\end{array}$ & $\begin{array}{l}19 / 80 \\
24 \%\end{array}$ & \\
\hline OR $(95 \%$ confidence interval $) \ddagger$ & & & 2.0 & $(0.7-5.7)$ & 3.0 & $(1.4-6.8)$ & $-\rrbracket$ & & \\
\hline
\end{tabular}

${ }^{\star}$ Data from eight patients were missing.

$+\mathrm{NA}=$ not available.

¥Because of the low number of women in the study of Graus $e t$ al, the odds ratios was also calculated by excluding this study: Female sex $=2.4$ (95\% CI 0.8-6.8), Limited disease: 3.7 (95\% CI 1.3-10.5).

$\S$ No odds ratio can be calculated. 


\section{Discussion}

The prevalence of low titre anti-Hu antibodies in patients with SCLC without paraneoplastic immunological complications was $17 \%$. This result is similar to the numbers reported by recent studies among North American and Spanish patients (table 3)..$^{2-4}$ We screened serum samples with an immunoblot assay, using purified recombinant $\mathrm{HuD}$, which has been shown to be highly specific and sensitive. ${ }^{4}$ An ELISA was used for semiquantitive analysis of the titre of anti-Hu antibodies. For the moderate and high anti-Hu antibody titres there was a good relation between the ELISA titre and intensity of the immunoblot reactivity. Two pretreatment serum samples with weak immunoblot staining, however, were negative in the ELISA. We prefer the immunoblot for screening, because the size of the stained band adds to the specificity of the assay.

If a pretreatment serum was found positive using the immunblot, all additional serum samples from the same patient were also positive. A decrease in titres was found during therapy, but only if ELISA was used. This is probably due to the multiple serum dilutions which where used in the ELISA but not in the western blot. The decrease was very likely due to the immunosuppressive effect of the chemotherapeutic drugs, as the highest titre clearly increased again after finishing chemotherapy. As measured by ELISA some titres were very low, but in the western blot no serum became negative. This indicates that it is not always necessary to use a pretreatment serum to determine if a patient has serum antibodies against $\mathrm{Hu}$-antigens, at least when an immunoblot with purified antigen is used. The titre of the serum with the highest pretreatment titre increased again to the original level after finishing chemotherapy. It could suggest that there is still tumour tissue present which stimulates the anti-Hu immune response. On the other hand, subclinical neuronal damage could provide the immune system with enough $\mathrm{Hu}$-antigen to ensure an ongoing (auto)immune response, independent of the presence of tumour tissue. A recent large study of 170 patients showed a clear association of anti-Hu serum antibodies and a limited stage of disease and complete response to therapy, resulting in an increase of median survival of 4.7 months. ${ }^{4}$ Another study of 36 patients with SCLC showed that patients with antibodies against autologous tumour cell proteins had a tendency towards improved survival. ${ }^{6}$ In our study of 52 patients we also found more patients with limited disease and complete response to therapy in the anti-Hu positive group. These numbers, however, did not reach significance. Possibly the number of patients was too small to show a significant effect. It cannot be excluded that the growth limiting effect of the anti-Hu immune response on the tumour is disturbed or even abolished by the chemotherapy. A therapy which would leave the immune response intact and only attack the tumour would be preferable in all patients with tumours, particularly those who demon- strate a good anti-Hu, and thus presumably, anti-tumour immune response. Possibly, somatostatin analogues ${ }^{7}$ or human anti-Hu monoclonal antibodies ${ }^{8}$ labelled with radioactive tracers, could be helpful in the development of these strategies.

Except for the study of Graus et $a l,{ }^{4}$ which contained only a few female patients, all studies found a predominance of women in the anti-Hu antibody positive group. All four studies found more patients with limited disease in the anti-Hu antibody positive group. We found no CNS metastases at the initial analysis of our patients, and this was also reported in one of the previous studies. ${ }^{2}$ Taken together, these results suggest an immune response directed against the $\mathrm{Hu}$-antigens elicited by the tumour, which, like many other autoimmune diseases, develops more often in women. Interestingly, female sex appears to be a good prognostic factor for SCLC. ${ }^{9}{ }^{10}$

This immune response is likely to result in some control of tumour growth, as most anti-Hu positive patients have a limited stage of disease at the time of tumour diagnosis. The lack of brain metastasis at the initial analysis could be caused by this protective antitumour immune response.

Similarly, a study in 85 patients with SCLC found significantly less metastases in the CNS in the subgroup of 28 patients with paraneoplastic syndromes (including inappropriate antidiuretic hormone secretion, Lambert-Eaton myasthenic syndrome, trombocytopenia, and other disorders). By contrast with our study, these patients had overt clinical paraneoplastic disease, which might have accelerated the diagnostic process, thus explaining the low prevalence of brain metastases. ${ }^{11}$

In conclusion, anti-Hu serum antibodies are present in $17 \%$ of patients with SCLC without paraneoplastic syndromes. Chemotherapy does not result in false negative anti-Hu antibody titres, provided serum is tested by western blot. Anti-Hu antibody positive patients tend to be women, to have limited disease at the time of tumour diagnosis, and initially metastases seem to spare the nervous system. This possibly indicates that the autoimmune antitumour response selects for tumour cells with non-neuronal features. Larger prospective studies are necessary to confirm these findings.

We thank Fons Kessels for statistical advice. JJV was supported to do this study by a Talent-stipendium of the Netherlands Organisation for Scientific Research.

1 Dalmau J, Graus F, Rosenblum MK, et al. Anti-Hu associated paraneoplastic enecephalomyelitis/sensory neuronopathy. A clinical study of 71 patients. Medicine 1992;71:59-72

2 Dalmau J, Furneaux HM, Gralla RJ, et al. Detection of anti-Hu antibody in the serum of patients with small cell 1990;27:544-52.

3 Mason WP, Verschuuren J, Graus F, et al. Anti-Hu antibodies in patients with small cell lung cancer, but no paraneoplastic disorder [abstract]. Proceedings of the 120th Annual meeting of the American Neurological Association; 1995 Oct 22-25. ANA, American 
4 Graus F, Dalmau J, Rene R, et al. Anti-Hu antibodies in patients with small-cell lung cancer: association with compatients with small-cell lung cancer: association with com-
plete response to therapy and improved survival. 7 Clin plete response to therapy

5 Greenland S, Rothland KJ. Introduction to categorical studies. In: Rothman KJ, Greenland J, eds. Modern epidemiology, 2nd ed. Philadelphia: Lippincott-Raven, 1998:23152.

6 Winter SF, Sekido Y, Minna JD, et al. Antibodies against autologous tumor cell proteins in patients with small-cel lung cancer: association with improved survival. 7 Nat Cancer Inst 1993;85:2012-18.

7 Zamora PO, Bender H, Gulhke S, et al. Pre-clinical experience with Re-188-RC-160, a radiolabeled somatostatin analog for use in peptide-targeted radiotherapy. Anticancer Res 1997; 17:1803-8.
8 Graus YF, Verschuuren JJ, Degenhardt A, et al. Selection of recombinant anti-HuD Fab fragments from a phage display antibody library of a lung cancer patient with paraneoplastic encephalomyelitis. F Neuroimmunol 1998;82: 200-9

9 Spiegelman D, et al. Prognostic factors in small-cell carcinoma of the lung: an analysis of 1,521 patients. F Clin Oncol 1989;7:344-354

10 Wolf M, Holle R, Hans K, et al. Analysis of prognostic factors in 766 patients with small cell lung cancer (SCLC): the role of sex as a predictor for survival. Br F Cancer 1991;63: 986-92.

11 de la Monte SM, Hutchins GM, Moore GW. Paraneoplastic syndromes and constitutional symptoms in prediction of metastatic behavior of small cell carcinoma of the lung. $\mathrm{Am}$ f Med 1984;77:851-7. 